Rev. Bras. Saúde Prod. Anim., Salvador, v.17, n.3, p.355-364 jul./set., $2016 \quad \underline{\text { http://www.rbspa.ufba.br }}$

\title{
Introdução de leguminosas forrageiras, calagem e fosfatagem em pastagem degradada de Brachiaria brizantha
}

\author{
Introduction of forage legumes, liming and phosphorus in degraded "Brachiaria \\ brizantha" pastures
}

\section{SOUZA, Flávia Martins de ${ }^{1}$; LEMOS, Barbara Juliana Martins ${ }^{1}$; OLIVEIRA JUNIOR, Reinaldo Cunha de ${ }^{2}$; MAGNABOSCO, Cláudio Ulhôa ${ }^{3}$; CASTRO, Letícia Mendes de ${ }^{5}$; LOPES, Fernando Brito ${ }^{4}$; BRUNES, Ludmilla Costa ${ }^{*}$}

\author{
${ }^{1}$ Universidade Federal de Goiás, Escola de Veterinária e Zootecnia, Programa de Pós-Graduação em \\ Zootecnia, Departamento de Produção Animal, Goiânia, Goiás, Brasil. \\ ${ }^{2}$ Pontifícia Universidade Católica, Goiânia, Goiás, Brasil. \\ ${ }^{3}$ Embrapa Cerrados, Planaltina, Distrito Federal, Brasil. \\ ${ }^{4}$ University of Wisconsin, College of Agricultural and Life Sciences, Madison, USA. \\ ${ }^{5}$ Embrapa Arroz e Feijão, Santo Antônio de Goiás, Goiás, Brasil. \\ *Endereço para correspondência: ludmillabrunes@hotmail.com
}

\section{RESUMO}

Existe a necessidade de intensificar a produtividade pecuária para alimentar a crescente população mundial. Sendo assim, objetivou-se avaliar a consorciação de pastagens Brachiaria com Estilosantes e Calopogônio sob aplicação de calagem e fosfatagem. Avaliou-se a produção de matéria orgânica e seca, densidade de perfilhos, teor de matéria seca e matéria mineral em pastagens degradadas de Brachiaria brizantha, com aplicação de calagem, fosfatagem e introdução de leguminosas. $\mathrm{O}$ delineamento experimental utilizado foi $o$ inteiramente casualizado com parcelas subdividida, em que foram avaliados dois tipos de leguminosas (Estilosantes Campo Grande e Calopogônio) e três tipos de adubação (Controle, $\mathrm{CaCo}_{3}, \mathrm{CaCo}_{3}+$ P). A calagem e fosfatagem foram realizadas na superfície da pastagem sem incorporação. A introdução das leguminosas foi feita em plantio direto após superpastejo. As avaliações foram realizadas quando o dossel atingiu $25 \mathrm{~cm}$ de altura com auxílio de um quadrado de $0,25 \mathrm{~m}^{2}$. As leguminosas não diferiram para produção de matéria natural e seca das pastagens de Brachiaria brizantha $(\mathrm{P}>0,05)$, mas os fatores de correção e adubação $\left(\mathrm{CaCo}_{3}+\mathrm{P}\right)$ melhoraram significativamente $(\mathrm{P}<0,05)$ a produção de massa das pastagens quando utilizou-se o Estilosantes Campo Grande em consorciação. Os resultados indicam a possibilidade de intensificar a produtividade pecuária usando leguminosas forrageiras, associadas com a fertilização $\mathrm{CaCO}_{3}$ $+\mathrm{P}$, uma vez que são capazes de recuperar e aumentar a produtividade de pastagens cultivadas em regiões tropicais.

Palavras-chave: Campo Grande, calopogônio, consorciação, estilosantes

\section{SUMMARY}

There is a need to intensify livestock productivity to feed the growing world population. Therefore, this study aimed to evaluate the intercropping of Brachiaria pastures with Estilosantes and Calopogonio under application of lime and phosphate. Thus, was evaluated the organic and dry matter production, tiller density, dry matter and mineral content in degraded Brachiaria brizantha pastures, applying lime and phosphate and introducing legumes. The entirely randomized experimental design was used and a split plot scheme, with two types of legumes (Estilosantes Campo Grande and Calopogonio) and three strategies of fertilization (Control, $\mathrm{CaCO} 3, \mathrm{CaCO} 3$ $+\mathrm{P})$. The lime and phosphate were performed on the pasture surface without incorporation. The introduction of legumes was carried by no-tillage practices after overgrazing. The evaluations were performed when the dossal reached $25 \mathrm{~cm}$ height with the assistance of a $0.25 \mathrm{~m}^{2}$ square. Legumes did not differ for the natural and dry matters 
Rev. Bras. Saúde Prod. Anim., Salvador, v.17, n.3, p.355-364 jul./set., $2016 \quad \underline{\text { http://www.rbspa.ufba.br }}$

production of Brachiaria brizantha $(\mathrm{P}>0.05)$, but the correction and fertilization factors $(\mathrm{CaCO} 3+$ $\mathrm{P})$ improved significantly $(\mathrm{P}<0.05)$ the pastures mass production when the Estilosantes Campo Grande were usedin intercropping. The results show that is possible to intensify livestock productivity using forage legumes, associated with $\mathrm{CaCO} 3+\mathrm{P}$ fertilization, to improve and recovery productivity of cultivated pastures in tropical regions.

Keywords: Campo Grande estilosantes, calopogonio, intercropping,

\section{INTRODUÇÃO}

Segundo a Organização das Nações Unidas, o mundo precisará produzir $70 \%$ mais alimentos para alimentar uma população estimada em 9,6 bilhões de pessoas em 2050 (SEARCHINGER et al., 2013). Por isso, existe a necessidade de verticalizar a produção de alimentos nos trópicos com o aumento da produtividade da agropecuária.

As pastagens constituem a principal fonte de alimentos para bovinos no Brasil, sendo a forma mais prática e econômica para os pecuaristas. Entretanto, cerca de $80 \%$ destas encontra-se em fase de degradação, levando a baixos índices de produtividade animal (PERON \& EVANGELISTA, 2004). A falta de persistência das gramíneas está relacionada em grande parte ao manejo inadequado, à perda da fertilidade do solo e à falta de adubação de reposição. Além disso, a baixa disponibilidade de nitrogênio $(\mathrm{N})$, fósforo $(\mathrm{P})$ e a alta saturação por alumínio (Al) representam os principais fatores que limitam a produtividade de forrageiras em solos de regiões tropicais (SANTOS et al., 2002), demonstrando a necessidade da calagem e adubação nitrogenada e fosfatada nesta região.

Apesar de ser eficiente na reposição de nutrientes, o uso de fertilizantes e corretivos pelos pecuaristas é muito limitado devido aos altos custos dos insumos, que podem representar mais de $60 \%$ do custo de produção (BARCELLOS et al., 2008). Em decorrência disto, estratégias de adubação mais econômicas têm sido estudadas a fim de auxiliar na recuperação de pastagens degradadas.

$\mathrm{O}$ uso de leguminosas forrageiras em consorciação com as pastagens pode ser utilizado como estratégia de adubação nitrogenada e ao mesmo tempo reduzir os custos com fertilizantes. As leguminosas possuem a capacidade de fixação de $\mathrm{N}$ atmosférico no solo, melhorando a qualidade da pastagem ao fornecer grandes quantidades de $\mathrm{N}$ ao sistema solo-planta-animal (GILLER \& CADISCH, 1995; CANTARUTTI et al., 2002). Esta contribuição eleva a capacidade de suporte da pastagem e prolonga sua vida produtiva (CANTARUTTI et al., 2002).

Sabe-se que $80 \%$ a $90 \%$ das áreas de pastagens no país são constituídas por capins do gênero Brachiaria, o que torna necessária a identificação da espécie leguminosa que melhor se adapta às condições edafoclimáticas do Cerrado e à consorciação com esta gramínea (BODDEY et al., 2004) bem como o desenvolvimento de estratégias eficientes para a recuperação dessas pastagens. Neste contexto, objetivou-se avaliar a consorciação de pastagens Brachiaria com Estilosantes e Calopogônio sob aplicação de calagem e fosfatagem.

\section{MATERIAL E MÉTODOS}

O experimento foi conduzido na Fazenda Escola da Universidade Estadual de Goiás, localizada no município de São Luís de Montes Belos - GO (Latitude sul:16 ${ }^{\circ}$ 31' 30"; 
Rev. Bras. Saúde Prod. Anim., Salvador, v.17, n.3, p.355-364 jul./set., $2016 \quad \underline{\text { http://www.rbspa.ufba.br }}$ ISSN 15199940

Longitude oeste: $50^{\circ} 22^{\prime} 20^{\prime \prime}$ ), entre o período de abril de 2009 e março de 2010. A região possui clima tropical do tipo Aw segundo a classificação de Köppen-Geiger, altitude de $580 \mathrm{~m}$, temperatura média anual de $24,3^{\circ} \mathrm{C}$ e a precipitação pluviométrica média anual é de 1.566mm (CLIMATE, 2014).

O campo experimental foi desenvolvido em uma área de pastagem Brachiaria brizantha cv Marandu (10 anos de implantação), cuja extensão total era de $288 \mathrm{~m}^{2}$. Esta área foi divida em 8 parcelas de 9 × 4 metros $\left(36 \mathrm{~m}^{2}\right.$ cada parcela), as quais foram divididas em subparcelas de $3 \times 4$ metros $\left(12 \mathrm{~m}^{2}\right)$, de modo que cada parcela apresentasse 3 subparcelas. Nas parcelas foram arranjadas as leguminosas (Estilosantes Campo Grande e Calopogônio) e nas subparcelas os fatores de correção e adubação do solo (calagem; calagem + fosfatagem; Controle - sem adubação). Desta forma, o campo experimental consistiu em um delineamento inteiramente ao acaso, arranjado em parcelas subdivididas, com quatro repetições.

Para proceder-se a correta adubação foi realizado um diagnóstico físico-químico do solo (amostragem de $0-20 \mathrm{~cm}$ de profundidade), o qual está apresentado na Tabela 1. As recomendações de calcário e fósforo foram realizadas conforme descrito por Vilela et al. (2004) para pastagens com gramíneas forrageiras tolerantes à acidez na região do Cerrado. As indicações foram de 1,535 toneladas/hectare de calcário para elevar a saturação de bases para $80 \%$ e de $700 \mathrm{~kg} /$ hectare de superfosfato simples (140kg de $\mathrm{P}_{2} \mathrm{O}_{5} / \mathrm{ha}$ ).

Tabela 1. Análise do solo do campo experimental em estágio de degradação

\begin{tabular}{|c|c|c|c|c|c|c|c|c|c|c|}
\hline \multicolumn{11}{|c|}{ Análise do Solo } \\
\hline \multicolumn{6}{|c|}{ cmolc/dm3 $(\mathrm{mE} / 100 \mathrm{ml})$} & \multicolumn{4}{|c|}{$\mathrm{mg} / \mathrm{dm} 3(\mathrm{ppm})$} & $\mathrm{g} / \mathrm{dm} 3$ \\
\hline $\mathrm{Ca}$ & $\mathrm{Mg}$ & $\mathrm{Al}$ & & $+\mathrm{Al}$ & $\mathrm{K}$ & $\mathrm{K}$ & P (Mel.) & \multirow{2}{*}{\multicolumn{2}{|c|}{ P (Resina) }} & Mat. Org. \\
\hline 3,0 & 1,1 & 0,0 & & 6 & 0,16 & 61,0 & 1,5 & & & 30,0 \\
\hline \multicolumn{11}{|c|}{ Dados Complementares } \\
\hline CTC & Sat. Base & & Sat. Al & $\mathrm{Ca} / \mathrm{Mg}$ & $\mathrm{Ca} / \mathrm{K}$ & $\mathrm{Mg} / \mathrm{K}$ & $\mathrm{Ca} / \mathrm{CTC}$ & $\mathrm{Mg} / \mathrm{CTC}$ & $\mathrm{K} / \mathrm{CTC}$ & $\mathrm{H}+\mathrm{Al} / \mathrm{CTC}$ \\
\hline 6,86 & $62,10 \%$ & & & 2,73 & 18,75 & 6,87 & $43,73 \%$ & $16,03 \%$ & $2,33 \%$ & $37,90 \%$ \\
\hline \multicolumn{5}{|c|}{$\mathrm{pH}$} & \multicolumn{5}{|c|}{ Textura $(\mathrm{g} / \mathrm{kg})$} & \\
\hline $\mathrm{H} 2 \mathrm{O}$ & $\mathrm{CaCl} 2$ & & $\mathrm{KCl}$ & & & & Limo & Areia & & \\
\hline- & 5,0 & & - & & & & 90,0 & 540,0 & & \\
\hline
\end{tabular}

A calagem e a fosfatagem foram realizadas com 60 dias de intervalo, sobre a superfície do solo sem utilizar nenhum método de incorporação. A introdução das leguminosas foi conduzida por plantio direto após superpastejo (MACEDO et al., 2000), utilizando $3,0 \mathrm{~kg} / \mathrm{ha}$ de sementes puras viáveis, objetivando um stand final de $20 \%$ a $40 \%$ de leguminosas.

As avaliações foram realizadas quando o dossel atingiu $25 \mathrm{~cm}$ de altura
(SILVA, 2006), durante os meses de novembro de 2009 a fevereiro de 2010 , com auxílio de um quadrado de $0,5 \mathrm{~m}$ de aresta $\left(0,25 \mathrm{~m}^{2}\right)$, lançado ao acaso 4 vezes em cada subparcela (GERDES et al., 2000). Foram consideradas ainda, bordaduras de $0,50 \mathrm{~m}$ entre cada parcela e entre as subparcelas.

Com o quadrado, procedeu-se a contagem de perfilhos, seguida do corte $\mathrm{da}$ forragem dentro da área do quadrado, com tesoura de poda na altura 
Rev. Bras. Saúde Prod. Anim., Salvador, v.17, n.3, p.355-364 jul./set., $2016 \quad \underline{\text { http://www.rbspa.ufba.br }}$

de $15 \mathrm{~cm}$ (SILVA, 2006). O material coletado foi pesado e amostrado para as avaliações da produtividade de matéria orgânica (MO) (GERDES et al., 2000) e matéria seca (MS), porcentagem de MS e matéria mineral (MM) e densidade de perfilhos. As determinações de MS e MM foram realizadas de acordo com AOAC (1990).

As médias das variáveis avaliadas, com exceção da densidade de perfilhos, foram submetidas à análise de variância e comparadas pelo teste de Scott-Knott, nível de significância $5 \%$, por meio do pacote estatístico R (2016). Para avaliar a densidade de perfilhos foi utilizado o teste de Kruskal Wallis, nível de 5\% de significância.

\section{RESULTADOS E DISCUSSÃO}

As leguminosas não diferiram $(\mathrm{P}>0,05)$ entre si para produção de matéria orgânica nas pastagens de Brazhiaria brizantha quando associadas às formas de adubação (Tabela 2). Entretanto, houve interação significativa $(\mathrm{P}<0,05)$ entre Estilosantes Campo Grande e $\mathrm{CaCo}_{3}+\mathrm{P}$, quando comparada as demais associações do Estilosantes com $\mathrm{CaCo}_{3}$ e Controle.O Estilosantes e a adubação de $\mathrm{CaCo}_{3}+\mathrm{P}$ aumentou $8.587,50 \mathrm{~kg}$ a produção de $\mathrm{MO}$ em pastagens de braquiária, em relação a adubação Controle associada ao Estilosantes. Enquanto que, ao avaliar a interação entre Calopogônio e os diferentes tipos de adubação não foram observadas diferenças significativas $(\mathrm{P}>0,05)$ na produção de pastagem. Contudo, observou-se que a aplicação de $\mathrm{CaCo}_{3}+\mathrm{P}$ foi responsável por melhorar em 48,69\% a produção de $\mathrm{MO}$ em pastagens de Brazhiaria brizantha, em relação a adubação Controle.
$\mathrm{Na}$ produção de matéria seca (MS) observou-se que a interação entre Estilosantes e $\mathrm{CaCO}_{3}+\mathrm{P}$ foi responsável em produzir $49,10 \%$ a mais $(\mathrm{P}<0,05)$ de $\mathrm{MS}$ em pastagem de braquiária, quando comprada ao Calopogônio e $\mathrm{CaCo}_{3}+\mathrm{P}$ (Tabela 3). No entanto, na interação observada entre Calopogônio e adição de $\mathrm{CaCo}_{3}$, a produção de MS foi significativamente maior $(\mathrm{P}<0,05)$ em relação ao Estilosante $+\mathrm{CaCo}_{3}$. Isso implica em dizer que, em condições de aplicação exclusiva de $\mathrm{CaCO}_{3}$, o consórcio com Calopogônio é superior ao Estilosantes. Ao avaliar as leguminosas associadas à adubação controle, não foram observadas diferenças significativas $(\mathrm{P}>0,05)$ entre elas.Comparando os tipos de adubos com cada leguminosa, foi observado que as interações das adubações $\mathrm{CaCo}_{3}$ e $\mathrm{CaCo}_{3}+\mathrm{P}$ com Calopogônio aumentou $(\mathrm{P}<0,05)$ em $2.765,2 \mathrm{~kg}$ e tendeu $(\mathrm{P}=0,06)$ a aumentar $2.060,5 \mathrm{~kg}$ a produção de MS ao comparar com a adubação Controle, respectivamente. Enquanto que, na consorciação de pastagens de Brachiaria brizantha com Estilosantes observou-se que apenas a interação com a adubação $\mathrm{CaCo}_{3}+\mathrm{P}$, foi responsável por aumentar significativamente $(159,14 \%)$ a produtividade da MS, em relação à adubação Controle. Corroborando com o presente trabalho, Flores et al. (2014) relataram que a aplicação de $\mathrm{CaCo} 3+\mathrm{P}$ foi responsável por melhorar a massa das pastagens consorciadas tanto com Calopogônio quanto com Estilosantes. De fato, Lopes et al. (2011) relataram que a adubação fosfatada garante maior população inicial de leguminosas forrageiras. Por conseguinte, há também maior fixação de nitrogênio no solo, melhorando as condições do solo para o desenvolvimento da gramínea. 
Rev. Bras. Saúde Prod. Anim., Salvador, v.17, n.3, p.355-364 jul./set., $2016 \quad \underline{\text { http://www.rbspa.ufba.br }}$ ISSN 15199940

Tabela 2. Produção de Matéria Orgânica (MO) em kg/ha (média \pm desvio padrão) de Brachiaria brizantha consorciada com Calopogônio ou Estilosantes Campo Grande com diferentes estratégias de adubação

\begin{tabular}{|c|c|c|c|}
\hline \multirow{2}{*}{ Adubação } & \multicolumn{2}{|c|}{ Leguminosa } & \multirow{2}{*}{ Média } \\
\hline & Calopogônio & Estilosantes & \\
\hline $\mathrm{CaCo}_{3}+\mathrm{P}$ & $13.712,5^{\mathrm{Aa}} \pm 2.136,7$ & $19.112,50^{\mathrm{Aa}} \pm 3.779,9$ & $16.413,0^{A} \pm 4.050,9$ \\
\hline $\mathrm{CaCO}_{3}$ & $14.550,0^{\mathrm{Aa}} \pm 3.935,9$ & $10.150,00^{\mathrm{Ba}} \pm 3.468,7$ & $12.350,0^{\mathrm{B}} \pm 4.162,6$ \\
\hline Controle & $11.550,0^{\mathrm{Aa}} \pm 902,8$ & $10.525,00^{\mathrm{Ba}} \pm 3.393,7$ & $11.038,0^{\mathrm{B}} \pm 2.363,4$ \\
\hline Média & $13.271,0^{\mathrm{a}} \pm 2.726,8$ & $13.263,0^{\mathrm{a}} \pm 5.386,2$ & \\
\hline
\end{tabular}

Médias distintas com letras maiúsculas nas colunas (adubação) e minúsculas nas linhas (leguminosas) diferem $(\mathrm{P}<0,05)$ pelo teste de Scott-Knott. Valor do Teste $\mathrm{F}$ para interação=3,83. *Tendências foram discutidas $(\mathrm{P}<0,06)$.

Tabela 3. Produção de matéria seca (MS) em $\mathrm{kg} / \mathrm{ha}$ (média \pm desvio padrão) de Brachiaria brizantha consorciada com Calopogônio ou Estilosantes Campo Grande com diferentes estratégias de adubação

\begin{tabular}{lccc}
\hline \multirow{2}{*}{ Adubação } & \multicolumn{2}{c}{ Leguminosa } & Média \\
\cline { 2 - 3 } & $6.086,4^{\mathrm{ABb}} \pm 1.206,2$ & $9.074,9^{\mathrm{Aa}} \pm 1.998,8$ & $7.580,6^{\mathrm{A}} \pm 2.206,9$ \\
$\mathrm{CaCo}_{3}+\mathrm{P}$ & $6.791,1^{\mathrm{Aa}} \pm 2.004,1$ & $3.213,1^{\mathrm{Bb}} \pm 1.048,1$ & $5.002,1^{\mathrm{B}} \pm 2.418,6$ \\
$\mathrm{CaCo}_{3}$ & $4.025,9^{\mathrm{Ba}} \pm 260,6$ & $3.501,9^{\mathrm{Ba}} \pm 1.136,7$ & $3.763,7^{\mathrm{B}} \pm 813,3$ \\
Controle & $5.634,5^{\mathrm{a}} \pm 1.735,6$ & $5.263,2^{\mathrm{a}} \pm 3.109,8$ & \\
\hline Média & Médias distintas com letras maiúsculas nas colunas (adubação) e minúsculas nas linhas (leguminosas) \\
diferem $(\mathrm{P}<0,05)$ pelo teste de Scott-Knott. Valor do Teste F para interação=8,50. & Tendências foram \\
discutidas $(\mathrm{P}<0,06)$.
\end{tabular}

As leguminosas forrageiras tropicais consorciadas com pastagens, além de serem capazes de melhorar a produção e qualidade das pastagens por fixar nitrogênio no solo, promovem também a diminuição da adsorção do fósforo, facilitando a sua solubilização, o que melhora o aproveitamento deste mineral pela gramínea (ARCAND et al., 2006; BARCELLOS et al., 2008). De acordo com Cromer et al. (1993), o P está relacionado com o surgimento das folhas, com a expansão foliar e com a taxa de fotossíntese por unidade de área foliar. Desta forma, a associação entre leguminosas e uma correta adubação podem maximizar a produção e a qualidade das forrageiras.

O curto período de implantação dos tratamentos ( 7 meses para calagem e 5 meses para fosfatagem e consorciação com leguminosas) e de coleta das amostras para avaliação, associado ao fato de se tratar de pastagem em recuperação, pode justificar a discreta influência da adubação sobre a produção da forrageira. Isso porque a resposta de pastagens recuperadas é maior no segundo ano, assim como demonstrado por vários outros estudos encontrados na literatura (OLIVEIRA et al., 2005; OLIVEIRA et al., 2007).

Quanto à densidade de perfilhos observadas (Tabela 4), houve diferenças significativas $(\mathrm{P}<0,05)$ em relação às formas de adubações. Nota-se que as estratégias de correção e adubação $\left(\mathrm{CaCo}_{3}+\mathrm{P}\right)$ foram capazes de aumentar o número de perfilhos quando comparadas ao tratamento $\mathrm{CaCo}_{3} \mathrm{e}$ Controle. A capacidade de originar novos perfilhos auxilia no 
Rev. Bras. Saúde Prod. Anim., Salvador, v.17, n.3, p.355-364 jul./set., $2016 \quad \underline{\text { http://www.rbspa.ufba.br }}$ ISSN 15199940

estabelecimento e na perenidade das gramíneas forrageiras, por assegurar maior proteção do solo contra a ação dos fatores do ambiente e maior controle de plantas daninhas através do sombreamento (ABREU et al., 2005). Isto significa que, a adubação fosfatada é capaz de auxiliar no processo de recuperação de pastagens.

Apesar da introdução de leguminosas não ter influenciado significativamente na densidade de perfilho, estas são importantes no desenvolvimento das pastagens. Segundo Batista \& Monteiro (2008) o suprimento de $\mathrm{N}$ é fundamental para que haja perfilhamento. Rodrigues et al. (2012) demonstraram que o nitrogênio e $o$ fósforo influenciam significativamente $(\mathrm{P}<0,05)$ o perfilhamento de Brachiaria brizantha, e concluíram que a adubação nitrogenada também é essencial para rebrota e crescimento da forrageira.

Tabela 4. Densidade de perfilhos observada de capim Brachiaria brizantha consorciada com Calopogônio ou Estilosantes Campo Grande com diferentes estratégias de adubação

\begin{tabular}{lccc}
\hline \multirow{2}{*}{ Adubação } & \multicolumn{2}{c}{ Leguminosa } & \multirow{2}{*}{ Média } \\
\cline { 2 - 3 } & Calopogônio & Estilosantes & $165,63 \pm 32,71$ \\
$\mathrm{CaCo}_{3}+\mathrm{P}$ & $175,00 \pm 38,80$ & $156,00 \pm 27,50$ & $129,50 \pm 15,17$ \\
$\mathrm{CaCo}_{3}$ & $134,00 \pm 11,34$ & $125,00 \pm 18,81$ & $133,38 \pm 30,97$ \\
Controle & $125,00 \pm 30,87$ & $141,75 \pm 33,15$ & \\
\hline Média & $144,67 \pm 34,96$ & $141,00 \pm 27,93$ & \\
\hline
\end{tabular}

Densidade de perfilhos não diferiu $(\mathrm{P}>0,05)$ para a interação (leguminosas $\mathrm{x}$ adubos) e para leguminosas e foi estatisticamente diferente $(\mathrm{P}<0,05)$ para as formas de adubação pelo teste de Kruskal-Wallis.

Além de auxiliar na recuperação das forrageiras, as leguminosas podem formar um banco de proteína para alimentação animal, aumentando a capacidade de suporte das pastagens, ou seja, a produtividade animal por área.

A Tabela 5 descreve os teores de MS das pastagens avaliadas. É provável que os altos teores de matéria seca observados se devem a um período prolongado de escassez de chuvas, antes da coleta das amostras. O tipo de leguminosa não influenciou o teor de matéria seca, exceto para interação das leguminosas com $\mathrm{CaCO}_{3}$, que foi superior $(\mathrm{P}<0,05)$ para o Calopogônio. Nota-se também que o $\mathrm{CaCO}_{3}$ foi responsável pela maior $(\mathrm{P}<0,05)$ concentração de matéria seca em pastagens consorciadas com Calopogônio em relação à adubação
Controle; não diferindo estatisticamente $(\mathrm{P}>0,05)$ da adubação $\mathrm{CaCo}_{3}+\mathrm{P}$. Enquanto que, na consorciação com Estilosantes Campo Grande a concentração de MS foi maior $(\mathrm{P}<0,05)$ para adubação $\mathrm{CaCo}_{3}+\mathrm{P}$. O teor de matéria mineral não foi influenciado $(\mathrm{P}>0,05)$ nos tratamentos avaliados (Tabela 6).

Geralmente o teor de MS de pastagens fertilizadas é menor em relação às pastagens que não receberam nenhuma forma de adubação (MARANHÃO et al., 2010; REZENDE et al., 2011). Os elevados teores de matéria seca em pastagens de solos de baixa fertilidade podem ser justificados pela senescência precoce da forrageira, ocasionado pela baixa disponibilidade de nutriente na planta, o que leva a um alto grau de lignificação. 
Rev. Bras. Saúde Prod. Anim., Salvador, v.17, n.3, p.355-364 jul./set., $2016 \quad \underline{\text { http://www.rbspa.ufba.br }}$ ISSN 15199940

Tabela 5. Concentração (\%) de Matéria Seca (média \pm desvio padrão) de Brachiaria brizantha consorciada com Calopogônio ou Estilosantes Campo Grande com diferentes estratégias de adubação

\begin{tabular}{|c|c|c|c|}
\hline \multirow{2}{*}{ Adubação } & \multicolumn{2}{|c|}{ Leguminosa } & \multirow{2}{*}{ Média } \\
\hline & Calopogônio & Estilosantes & \\
\hline $\mathrm{CaCo}_{3}+\mathrm{P}$ & $44,3^{\mathrm{Aa}} \pm 4,7$ & $47,6^{\mathrm{Aa}} \pm 6,7$ & $45,9^{\mathrm{A}} \pm 5,7$ \\
\hline $\mathrm{CaCo}_{3}$ & $46,9^{\mathrm{Aa}} \pm 6,6$ & $31,9^{\mathrm{Bb}} \pm 1,8$ & $39,4^{\mathrm{B}} \pm 9,2$ \\
\hline Controle & $34,9^{\mathrm{Ba}} \pm 0,5$ & $33,3^{\mathrm{Ba}} \pm 1,6$ & $34,1^{\mathrm{C}} \pm 1,4$ \\
\hline Média & $42,1^{\mathrm{a}} \pm 6,89$ & $37,6^{b} \pm 8,2$ & - \\
\hline
\end{tabular}

Médias distintas com letras maiúsculas nas colunas (adubação) e minúsculas nas linhas (leguminosas) diferem $(P<0,05)$ pelo teste de Scott-Knott. Valor do Teste F para interação=8,28.

Tabela 6. Concentração (\%) de Matéria Mineral (média \pm desvio padrão) de Brachiaria brizantha consorciada com Calopogônio ou Estilosantes Campo Grande com diferentes estratégias de adubação

\begin{tabular}{lccc}
\hline \multirow{2}{*}{ Adubação } & \multicolumn{2}{c}{ Leguminosa } & \multirow{2}{*}{ Média } \\
\cline { 2 - 3 } & Calopogônio & Estilosantes & $7,86 \pm 2,5$ \\
$\mathrm{CaCo}_{3}+\mathrm{P}$ & $9,0 \pm 2,8$ & $6,72 \pm 1,5$ & $8,59 \pm 1,2$ \\
$\mathrm{CaCo}_{3}$ & $8,8 \pm 1,1$ & $8,34 \pm 1,4$ & $7,92 \pm 2,1$ \\
Controle & $7,2 \pm 2,4$ & $8,93 \pm 1,4$ & \\
\hline Média & $8,34 \pm 2,2$ & $7,91 \pm 1,6$ & \\
\hline
\end{tabular}

Médias distintas com letras maiúsculas nas colunas (adubação) e minúsculas nas linhas (leguminosas) diferem $(P<0,05)$ pelo teste de Scott-Knott. Valor do Teste F para interação=2,18.

No entanto, no presente trabalho, as maiores concentrações de MS foram observadas para as pastagens adubadas. Sendo assim, deve ser considerado que, para os trabalhos descritos anteriormente, os cortes para avaliação foram realizados em período menor que 30 dias, significando que as plantas forrageiras apresentaram maior proporção folha:colmo e menor maturidade, observando menor teor de MS. Já o presente estudo compreendeu um período de 90 dias para avaliação. Sabe-se que, o avanço na idade da folha leva ao incremento nos componentes da parede celular, queda nos coeficientes de digestibilidade e nos teores de proteína bruta, o que resulta num maior teor de MS (WILMAN \& MOGHADDAM, 1998). Desta forma, o maior teor de MS obtido com as diferentes adubações avaliadas está relacionado à maior produtividade de massa da forrageira.

A correção e adubação do solo proporcionaram um aumento efetivo na produção da pastagem de Brachiaria brizantha. A consorciação de pastagens com Estilosantes Campo Grande foi mais responsiva às adubações com fósforo e pouco diferiu da consorciação com Calopogônio. A combinação entre adubação e o consórcio com leguminosas não influenciou na densidade de perfilhos da pastagem de $B$. brizantha.

Leguminosas forrageiras associadas à adubação $\mathrm{CaCo}_{3}+\mathrm{P}$ podem ser usadas como alternativa na melhoria $\mathrm{e}$ recuperação de pastagens cultivadas em regiões tropicais, sugerindo a possibilidade de intensificação da produtividade pecuária. 
Rev. Bras. Saúde Prod. Anim., Salvador, v.17, n.3, p.355-364 jul./set., $2016 \quad$ http://www.rbspa.ufba.br ISSN 15199940

\section{REFERÊNCIAS}

ABREU, J.G.; EVANGELISTA, A.R.; SOUZA, I.F.; ROCHA, G.P.; SOARES, L.Q.; SANTAROSA, L.C. Glyphosate e nitrogênio no controle de Brachiaria decumbensstapf em capineiras estabelecidas. Ciência e Agrotecnologia, v.30, n.5, p.977-987, 2006.

ASSOCIATION OF OFFICIAL ANALYTICAL CHEMISTS - AOAC. Official methods of analysis. 15th ed. Arlington, 1990. 1117p.

ARCAND, M.M.; SCHNEIDER, K.D. Plant and microbial bases mechanisms to improve the agronomic effectiveness of phosphate rock: a review. Annals of the Brazilian Academy of Sciences, v.78, n.4, p.791-807, 2006.

BARCELLOS, A.O.; RAMOS, A.K.B.; VILELA, L.; JUNIOR, G.B.M. Sustentabilidade da produção animal baseada em pastagens consorciadas e no emprego de leguminosas exclusivas, na forma de banco de proteína, nos trópicos brasileiros. Revista Brasileira de

Zootecnia, v.37, p.51-67, 2008.

BATISTA, K.; MONTEIRO, F.A. Nitrogênio e enxofre nas características morfogênicas do Capim-marandu em substituição ao Capim-braquiária em degradação em solo com baixo teor de matéria orgânica. Revista Brasileira de Zootecnia, v.37, n.7, p.1151-1160, 2008.

BODDEY, R.M.; MACEDO, R.;

TARRÉ, R.; FERREIRA, E.;

OLIVEIRA, O.C.; RESENDE, C. de P.; CANTARUTTI, R.B.; PEREIRA, J.M.; ALVES, B.J.R.; URQUIAGA, S.

Nitrogen cycling in Brachiaria pastures: the key to understanding the process of pasture decline. Agriculture,

Ecosystems and Environment, v.103, p.389-403, 2004.
CANTARUTTI, R.B.; TARRÉ, R.M.; MACEDO, R.; CADISCH, G.; RESENDE, C.P.; PEREIRA, J.M.; BRAGA, J.M.; GOMEDE, J.A.; FERREIRA, E.; ALVES, B.J.R.; URQUIAGA, S.; BODDEY, R.M. The effect of grazing intensity and the presence of a forage legume on nitrogen dynamics in Brachiaria pastures in the Atlantic forest region of the South of Bahia, Brazil. Nutrient Cycling in Agroecosystem, v.64, p.257-271, 2002.

CLIMATE: São Luís de Montes Belos. On line. Disponivel em: $<\mathrm{http}$ ://en.climatedata.org/location/43433/>. Acesso em: 30 jul. 2014.

CROMER, R.N.; KRIEDEMANN, P.E.; SANDS, P.J.; STEWART, L.G. Leaf growth and photosynthetic response to nitrogen and phosphorus in seedling trees of Gamelia arborea. Austyralian

Journal of Plant Physiology, v.20, p.8398, 1993.

FLORES, R.A.; COLLIER, L.S.; SANTOS, C.L.R.; MODA, L.R.; SILVA, Á.R. Yield of Andropogon gayanus pasture intercropped with two kinds of legumes, amended with $\mathrm{P}$ fertilizer. Journal Biotechnology Biodivers, v.5, n.1, p.50-62, 2014.

GERDES, L.; WERNER, J.C.; COLOZZA, M.T.; CARVALHO, D.D.; SCHAMMASS, E. P. Avaliação de características agronômicas e morfológicas das gramíneas forrageiras Marandu, Setária e Tanzânia aos 35 dias de crescimento nas estações do ano.

Revista Brasileira de Zootecnia, v.29, p.947-954, 2000.

GILLER, K.; CADISCH, G. Future benefits from biological nitrogen fixation: an ecological approach to agriculture. Plant and Soil, v.174, p.255-277, 1995. 
Rev. Bras. Saúde Prod. Anim., Salvador, v.17, n.3, p.355-364 jul./set., $2016 \quad$ http://www.rbspa.ufba.br ISSN 15199940

LOPES, J.; EVANGELISTA, A.R.; PINTO, J.C.; QUEIROZ, D.S.; MUNIZ, J.A. Doses de fósforo no estabelecimento de Capim-Xaraés e estilosantes Mineirão em consórcio.

Revista Brasileira de Zootecnia, v.40, n.12, p.2658-2665, 2011.

MACEDO, M.C.M.; KICHEL, A.N.; ZIMMER, A.H. Degradação e alternativas de recuperação e renovação de pastagens. Campo grande: EMBRAPA-CNPGC, 2000. p.1-4. (Comunicado técnico, 62).

MARANHÃO, C.M.A.; BONOMO, P.; PIRES, A.J.V.; COSTA, A.C.P.R.; MARTINS, G.C.F.; CARDOSO, E.O. Características produtivas do capimbraquiária submetido a intervalos de cortes e adubação nitrogenada durante três estações. Acta Scientiarum.

Animal Sciences, v.32, n.4, p.375-384, 2010.

OLIVEIRA, P.P.A.; OLIVEIRA, W.S.; CORSI, M. Efeito residual de fertilizantes fosfatados solúveis na recuperação de pastagem de Brachiaria brizantha cv. Marandu em Neossolo Quartzarênico. Revista Brasileira de Zootecnia, v.36, n.6, p.1715-1728, 2007.

OLIVEIRA. P.P.A.; TRIVELIN, P.C.O.; OLIVEIRA, W.S.; CORSI, M. Fertilização com N e S na recuperação de pastagem de Brachiaria brizantha cv. Marandu. Revista Brasileira de Zootecnia, v.34, n.4, p.1121-1129, 2005.

PERON, A.J.; EVANGELISTA, A.R. Degradação de pastagens em regiões de cerrado. Ciência e Agrotecnologia, v.28,n.3, p.655-661, 2004.
R DEVELOPMENT CORE TEAM. R: A language and environment for statistical computing. R Foundation for Statistical Computing, Vienna, Austria. Aviable in: $<$ http://www.Rproject.org>. 2016.

REZENDE, A.V.; LIMA, J.F.; RABELO, C.H.S.; RABELO, F.H.S.; NOGUEIRA, R D.A.; CARVALHO, M.; FARIA JUNIOR, D.C.N.A.; BARBOSA, L.Á. Características morfofisiológicas da Brachiaria brizantha $\mathrm{cv}$. Marandu em resposta à adubação fosfatada. Revista Agrarian, v.4, n.14, p.335-343, 2011.

RODRIGUES, R.C.; LIMA, D.O.S.; CABRAL, L.S.; PLESE, L.P.M.; SCARAMUZZA, W.L.M.P.; UTSONOMYA, T.C.A.; SIQUEIRA, J.C.; JESUS, A.P.R. Produção e morfofisiológica do capim Brachiaria brizantha cv. Xaraés sob doses de nitrogênio e fósforo. Revista Brasileira de Agropecuária Sustentável, v.2, n.1., p.124-131, 2012.

SANTOS, I.P.A.; PINTO J.C.; SIQUEIRA, J.O.; MORAIS A.R.; SANTOS, C.L. Influência do fósforo, micorriza e nitrogênio no conteúdo de minerais de Brachiaria brizantha e Arachis pintoi consorciados. Revista Brasileira de Zootecnia, v.31, n.2, p.605-616, 2002.

SEARCHINGER, T.; HANSON, C.; RANGANATHAN, J.; LIPINSKI, B.; WAITE, R.; WINTERBOTTOM,R.; DINSHAW,A.; HEIMLICH, R. Creating a Sustainable Food Future: Interim Findings - ONU report Organização das Nações Unidas. Aviable in: $<$ http://www.wri.org/publication/creating -sustainable-food-future-interimfindings $>$. Access: Dezembro de 2013. 
Rev. Bras. Saúde Prod. Anim., Salvador, v.17, n.3, p.355-364 jul./set., $2016 \quad \underline{\text { http://www.rbspa.ufba.br }}$

SILVA, S.C. da. Manejo do pastejo para obtenção de forragem de qualidade. In: SIMPÓSIO GOIANO SOBRE MANEJO E NUTRIÇÃO DE BOVINOS, 8, 2006, Goiânia.

Anais...Goiânia: CBNA, 2006. p.101130.

VILELA, L.; SOARES, W.V.; SOUSA, D.M.G.; MACEDO, C.M. Calagem e adubação para pastagens. In: SOUSA, D.M.G.; LOBATO, E. (Ed.). Cerrado: correção e adubação. $2^{\mathrm{a}}$ ed. Brasília-DF: Embrapa Informações Tecnológica, 2004. p317- 382.

WILMAN, D., MOGHADDAM, P.R. In vitro digestibility and neutral detergent fibre and lignin contents of plant parts of nine forage species.

Journal Agricultural Science, v.131, p.51-58, 1998.

Data de recebimento: 27/02/2015

Data de aprovação: 10/08/2016 